\title{
A Study on Age Wise Seroprevalence and Seropositivity for Toxoplasma and Rubella among Torch Infections in Women with Bad Obstetric History
}

\author{
Rafath Fatima $^{1 *}$ and G. Sasi Kala ${ }^{2}$ \\ ${ }^{1}$ VRDL Laboratory, Osmania Medical College, Hyderabad, Telangana, India \\ ${ }^{2}$ Department of Microbiology, Osmania Medical College, Hyderabad, Telangana, India
}

*Corresponding author

\begin{tabular}{|l|}
\hline Ke y w o r d s \\
TORCH, BOH, \\
Seropositivity, \\
ELISA, \\
Toxoplasma, \\
Rubella \\
\hline Article Info \\
\hline $\begin{array}{l}\text { Accepted: } \\
\text { 12 June } 2019 \\
\text { Available Online: } \\
\text { 10 July } 2019\end{array}$ \\
\hline \hline
\end{tabular}

\section{A B S T R A C T}

\begin{abstract}
Maternal infections caused by TORCH [Toxoplasma gondii, Rubella virus, Cytomegalovirus (CMV), Herpes simplex virus (HSV)] are the major causes of bad obstetric history. The aim of this study was to evaluate the age wise seroprevalence and to assess the seropositivity of Toxoplasma and Rubella among TORCH infections in pregnant women with $\mathrm{BOH}$. A total of 90 sera samples are collected from pregnant women with bad obstetrical history attending the antenatal clinic in Govt. Maternity Hospital, Sultan Bazar, Kothi, Hyderabad. Patients included in this study were those with history of stillbirths, habitual abortions, intrauterine growth retardation and neonatal deaths. Serological analysis of Toxoplasma and Rubella among TORCH infections by IgM and IgG was carried out at Regional STD laboratory of Osmania General Hospital, Hyderabad. In the present study it was found that the prevalence of TORCH infection was more common in $19-24$ years - 51 (56.7\%). Total study population majority of the pregnant females had previous history of two or more spontaneous abortions 63 (70\%) followed by intrauterine deaths $40(44.4 \%)$. Among these patients $11(12.2 \%)$ had history of both spontaneous abortions and intrauterine deaths. Of the $90 \mathrm{BOH}$ cases, serological evidence for any one of the TORCH agents was detected in $80(88.8 \%)$ pregnant females. Seronegativity to $\mathrm{IgM} / \mathrm{IgG}$ was observed in ten cases $(11.1 \%)$. The $\mathrm{IgM} / \mathrm{IgG}$ antibody positivity to Toxoplasma gondii 5 (5.6\%) / 28 (31.1\%), Rubella 8 (8.9\%) / 48 (53.3\%). In the present study out of 90 antenatal women with BOH 28 (31.1\%), were seropositive for Toxoplasma specific IgG, 5 (5.6\%) cases were seropositive for Toxoplasma specific IgM antibodies and 1 case (1.1\%) was seropositive for both IgG and IgM. Majority of seropositive Toxoplasma and Rubella cases were seen in the age group $19-24$ years. In the present study Toxoplasma gondii, which is a known etiological agent in recurrent pregnancy wastage was found positive in $28(31.1 \%) \mathrm{IgG}$ and $5(5.6 \%) \mathrm{IgM}$ pregnant women with $\mathrm{BOH}$ [18 (20\%)]. Overall seropositivity of Rubella concluded in this study is $56(63 \%)$. Out of these 56 cases of BOH 34 had a history of two or more spontaneous abortions while 21 of them had a history of intrauterine deaths and one case had a history of congenital malformation. In the present study, of the 90 cases of BOH the seropositivities of the pregnant women for anti-rubella IgM is $8(8.9 \%)$, while $\operatorname{IgG}$ is $48(53.3 \%)$. Of these Rubella seropositive females $6(6.7 \%)$ were positive for both IgG \& IgM. The present study demonstrates a strong association between the $\mathrm{TORCH}$ infectious agents and women having $\mathrm{BOH}$. All the patients with previous history of recurrent pregnancy miscarriage should be subjected to TORCH screening. All antenatal cases with BOH, should be routinely screened for TORCH agents as early diagnosis to reduce adverse fetal outcome, diminishing the morbidity and mortality.
\end{abstract}

\section{Introduction}

TORCH infections are unique in their pathogenesis and have potentially devastating clinical manifestations. In most cases maternal infection is mild but the impact on the developing foetus is enormous with vast array of symptoms. TORCH infections during pregnancy are a potential cause for congenital infections, abortions, intrauterine growth restriction (IUGR), still births and intrauterine deaths (IUD). Diagnosis of acute TORCH infection in pregnant women is usually established by demonstration of sero- 
conversion in paired sera or by demonstration of specific IgM antibodies. TORCHES have been recognized to be one of the main causes of bad obstetric history. This group of infections gains access to the foetal blood stream trans-placentally via the chorionic villi (Padmavathy et al., 2013)

Bad obstetric history $(\mathrm{BOH})$ is defined as previous unfavourable outcomes in terms of two or more consecutive spontaneous abortions, history of intrauterine foetal death, intrauterine growth retardation, stillbirths, early neonatal death and/or congenital anomalies (Daftary, 1991).

These maternal infections are initially in apparent, mild or asymptomatic and thus are difficult to diagnose on clinical basis. Diagnosis of these infections depends on serological evidence.

Seroconversion in paired sera or demonstration of specific IgM antibodies by Enzyme Linked Immunosorbent Assay (ELISA) is highly specific and sensitive (Sen et al., 2012).

Due to lack of National Screening programs, there is no baseline serological data regarding prevalence of TORCHES infections in India5. Prevalence of these infections varies from one geographical area to another (Sen et al., 2012). Studies conducted in different parts of the country have shown significant association of TORCHES and BOH (Kumari et al., 2011).

\section{In a study done by Namrata}

Kumari et al., titled 'Is screening of TORCH worthwhile in women with bad obstetric history: An observational study' concluded that seropositivity rate of TORCH infections in women with $\mathrm{BOH}$ was higher $(83.3 \%)$ when compared to that in normal healthy controls (Kumari et al., 2011).
Serological status of these infections in pregnant women provides information about the immune status which may help to identify women at risk and aid in preventing congenital infections due to TORCH agents (Fatima et al., 2014). Hence, the present study is undertaken to evaluate the seroprevalence of and seropositivity of Toxoplasma and Rubella among TORCHES infections in pregnant women with $\mathrm{BOH}$ attending antenatal clinic of Government Maternity Hospital, Sultanbazar, Koti, Hyderabad.

The main objectives of this study are to evaluate the prevalence of TORCHES infections in pregnancy wastages in women with $\mathrm{BOH}$.

To assess the age wise seroprevalance and seropositivity of Toxoplasma and Rubella of TORCHES infection in pregnant women with $\mathrm{BOH}$.

\section{Materials and Methods}

\section{Study design}

The present study has been conducted at Government Maternity Hospital, Koti, Hyderabad, (from March 2014 - August 2014).

\section{Type of study}

This was a Prospective non-randomized study, conducted in 90 pregnant women attending the antenatal clinics or sought admission to the antenatal wards and study should carry under the guidance of Institutional ethical committee.

\section{Inclusion criteria}

Women attending antenatal clinic with $\mathrm{BOH}$, irrespective of duration and condition of pregnancy. 
Willing and able to provide written and informed consent.

\section{Exclusion criteria}

Medical Termination of Pregnancies.

Not willing to provide consent.

Serum specimens that are excessively haemolysed, grossly contaminated with bacteria, chylous or otherwise extremely turbid.

Patients were selected based on the criteria of $\mathrm{BOH}$ - previous history of pregnancy wastage i.e. with history of previous unfavorable foetal outcome in terms of two or more consecutive spontaneous abortion, history of intrauterine foetal death, intrauterine growth retardation, still births, early neonatal death and/or congenital anomalies. A study proforma was prepared and patients were questioned accordingly. Cases suffering from other causes of abortions like cervical incompetence, $\mathrm{Rh}$ incompatibility, diabetes were not included in the study.

\section{Collection and transport of specimen}

Patients were explained about collection of $5 \mathrm{ml}$ blood by venipuncture and the purpose, importance and benefit of getting screened for TORCHES infections. The test is done free of cost and in case of rejection of consent; treatment and care shall not be affected. $5 \mathrm{ml}$ of venous blood was collected under aseptic precautions in vacccutainers (BD vacutainer $13 \times 75 \mathrm{~mm}$ ) with no additives and kept at room temperature for $30 \mathrm{~min}$ to clot. Serum separated by centrifugation at 3000rpm for $5 \mathrm{~min}$ and transferred to plastic aliquots. Each serum sample was distributed in six different aliquots for each of the respective tests and a stock sample. The aliquots were labelled with appropriate information of patient and were stored at $-20^{\circ} \mathrm{C}$ until tested.
Serum samples from subjects were tested using the commercial kits for qualitative immunoenzymatic determination of $\operatorname{IgM}$ and IgG antibodies for Toxoplasma gondii, and Rubella. The commercial kits used were DIA. PRO, Diagnostic Bioprobes Srl San Giovanni, (Milano) - Italy. IgG and IgM detection kits were bought for each of the respective organism. Principle and procedure of each of the specific $\operatorname{IgG}$ or IgM tests were same. Procedure of one specific Ig $G$ or Ig $M$ is described and literature of each of the four organisms provided by the kit.

\section{Results and Discussion}

Following are the observations and results of the present study (Table 1-13).

The predominant clinical condition responsible for $\mathrm{BOH}$ with Rubella infection was abortions in 34 cases $(60.7 \%)$ followed by IUD [21(37.5\%)]

Serological surveys play a definite role in defining infectious disease epidemiology and consequence of these diseases. In India, pregnant women belonging to low socioeconomic group may be exposed to a variety of infections due to poor environment and hygiene and these maternal infections are significant factors in the causation of poor pregnancy outcome ${ }^{63}$. All pathogens usually cause a primary maternal viremia which may infect the placenta and thereby the foetus with the exception of Herpes Simplex Virus - 2, which causes an ascending infection via the genital tract to foetal membranes and then to the foetus. Infections by TORCH agents in women are usually asymptomatic and chronic. The social and reproductive maladjustment because of repeated pregnancy wastages, cost of treatment, and morbidity caused to the infant make the TORCH group of infections a major cause of concern (Turbadkar et al., 2003). 
TORCH screening in antenatal period helps to identify high risk mothers and institute the required treatment modality for the foetus. Many sensitive and specific tests are available for serological diagnosis of TORCH complex. TORCH test, which is called the TORCH panel, belongs to a category of blood tests called Infectious-Disease Antibody Titre tests - IDAT. TORCH tests measure the presence of antibodies against a specific group of infectious diseases and their level of concentration in the blood Surpam et al., (2006). IgM is the first antibody produced as a result of body's immune response, which lasts for a short time (1 - 3 weeks).

Presence of IgM indicates acute infection. In an immune response, $\operatorname{IgM}$ is followed by $\mathrm{IgG}$. A positive $\mathrm{IgG}$ antibody test is usually a sign of past exposure to the TORCH agent and is not a marker for current active infection. IgG antibodies remain detectable for a lifetime, providing immunity and preventing or reducing the severity of reinfection.

A total of 90 sera samples are collected from pregnant women with bad obstetrical history attending the antenatal clinic in Govt. Maternity Hospital, Sultan Bazar, Kothi, Hyderabad. Patients included in this study were those with history of stillbirths, habitual abortions, intrauterine growth retardation and neonatal deaths. Serological analysis of TORCH infections by IgM and IgG ELISA and VDRL and TPHA for syphilis was carried out at Regional STD laboratory of Osmania General Hospital, Hyderabad.

\section{Age wise distribution of cases}

In the present study it was found that the prevalence of TORCH infection was more common in 19 - 24 years - $51(56.7 \%)$ with a mean age of 22.7 years followed by $36(40 \%)$ in 25 - 30 years. Sen et al., in 2012 concluded similar results they mentioned "The seropositivities for each component of the TORCH infections were seen in a majority of the cases which were in the 19-25 years age group". Similar results were observed by $\mathrm{P}$ Yasodhara et al., in 2001 i.e. mean age was $22.3 \pm 3.5$ years. Nazish et al., ${ }^{8}$ in 2014 concluded $53.84 \%$ of TORCH positive cases belonged to age group 21-25 years. In 2008 Denoj Sebastian K. F. Zuhara and K. Sekaran observed similar results with $49.38 \%$ in 20 24 years age group.

\section{Obstetric history of $\mathrm{BOH}$ cases}

In the present study among all the 90 cases selected under $\mathrm{BOH}$ with reference to definition i.e. having two or more consecutive spontaneous abortion, history of intrauterine foetal death, intrauterine growth retardation, still births, and / or congenital anomalies majority of the pregnant females had previous history of two or more spontaneous abortions $63(70 \%)$ followed by intrauterine deaths 40 (44.4\%). Among these patients 11 (12.2\%) had history of both spontaneous abortions and intrauterine deaths.

Shashi Chopra et al., in 2004 have shown similar observations with maximum. With maximum. seropositivity in cases with previous history of abortions $61(71.8 \%)$. Similar results were observed in a study done by Padmavathy et al., in 2013 with 47 (54.1\%) spontaneous abortions and $20 \quad(23.0 \%)$ intrauterine deaths. These studies similar with previous studies carried out by Nazish et al., (2014) study consisted of abortion in 22(7.26\%).

\section{Serological evidence of TORCH infections}

Of the $90 \mathrm{BOH}$ cases, serological evidence for any one of the TORCH agents was detected in $80(88.8 \%)$ pregnant females. Seronegativity to $\mathrm{IgM} / \mathrm{IgG}$ was observed in ten cases (11.1\%). Similar results were concluded by 
Namrata Kumari et al., (2011) in 2011 with $83.3 \%$ serologically positive at least for one of the TORCH agents. Kaur et al., (1999) observed $112(93.4 \%)$ seropositive of 120 cases. The IgM / IgG antibody positivity to Toxoplasma gondii 5 (5.6\%) / 28 (31.1\%), Rubella 8 (8.9\%) / 48 (53.3\%), Cytomegalovirus $9(10 \%) / 60(66.7 \%)$ and Herpes Simplex Virus - 26 (6.7\%) / 7 (7.8\%). It was observed that, antibody positivity was highest for Cytomegalovirus $9(10 \%)$ / 60 (66.7\%). Similar results were observed by Padmavathy et al., in 2013 highest (33.3\%).

Kishore et al., (2011) in 2011 study showed a positivity rate of $30 \%$ for Cytomegalovirus specific IgM which was higher than other TORCH agents. M.R. Sen et al., ${ }^{6}$ in 2012, MS Sadik et al., (2012) as well had majority of seropositives for Cytomegalovirus. Out of 46 patients of mixed infections, 4 were positive for Toxoplasma and Rubella, 5 for Toxoplasma and Cytomegalovirus, 24 for Rubella and Cytomegalovirus and in 11 samples antibodies to all the three agents were detected in significant titres. Similar observations of mixed infections have been made in 2004 by Sashi Chopra et al., (2004) and Padmavathy et al., (2013).

\section{Toxoplasma}

In India, the exact seroprevalence of toxoplasmosis is not known. However, a prevalence which is as low as 5\% and which is as high as $80 \%$ in adults, has been reported (Turbadkar et al., 2003). Several studies in India showed the seroprevalence of toxoplasmosis as $2.9 \%$ to $42.5 \%$ in women of reproductive age, the lowest being in the northern parts of India and the highest in the south (Singla et al., 2004). This agent has predilection for nucleated cells of muscle, intestinal epithelium and placenta. Persistence of encysted Toxoplasma gondii in chronically infected uteri, and their subsequent rupture during placentation lead to infection of the infant in the first trimester and often to recurrent miscarriages (Tubaida et al., 2011). The risk of toxoplasma seroconversion in pregnant mothers has been reported to be 2.2 times higher than in non-pregnant women, in the same age group and risk increased to 7.7 in adolescents (Singla et al., 2004).

In the present study out of 90 antenatal women with $\mathrm{BOH} 28(31.1 \%)$, were seropositive for Toxoplasma specific IgG, $5(5.6 \%)$ cases were seropositive for Toxoplasma specific IgM antibodies and 1 case $(1.1 \%)$ was seropositive for both IgG and IgM. Results of the present study are comparable to the observations made by Dr. Sankar in 2004 who reported a seropositivity of $38 \%$ for $\operatorname{IgG}$ and Yasodhara et al., (2001) who reported a seropositivity of $18.3 \%$ for Toxoplasma specific IgM antibodies. Suryamani Chintapalli and Jyothi Padmaja (2013) concluded similar results with 36 (45\%), seropositive for Toxoplasma specific IgG, 16 cases (20\%) seropositive for Toxoplasma specific IgM antibodies. Turbadkar et al., (2003) in 2003 out of 380 cases of $\mathrm{BOH}$ observed $\operatorname{IgM} 40$ (10.5\%), IgG $160(42.1 \%)$.

Similarity of seropositivity of anti-toxoplasma antibodies in present study and other studies from different parts of India.

\section{Age wise distribution of toxoplasma cases}

Majority of seropositive cases were in the age group 19 - 24 years $\{18(20 \%)\}$. Abdul Hamid et al., in 1999 observed similar results with majority of women in age group 20 - 24 years. Similar results were concluded by Suryamani Chintapalli and Jyothi Padmajain in 2013 with maximum seropositives in the age group 20 24 years. Sarman Singh et al., (2014) in 2014 concluded most women were in the $18-25$ years age group (48.3\%). 
Table.1 Age wise distribution of cases $(n=90)$

\begin{tabular}{|c|c|}
\hline Age in years & No. of cases $(\boldsymbol{\%})$ \\
\hline $19-24$ & $51(56.7)$ \\
\hline $25-30$ & $36(40)$ \\
\hline $31-35$ & $3(3.3)$ \\
\hline Total & $90(100)$ \\
\hline
\end{tabular}

Table.2 Obstetric history of both cases in various age groups $(n=90)$

\begin{tabular}{|l|c|c|r|r|}
\hline \multirow{2}{*}{ Clinical Presentation } & \multicolumn{2}{|c|}{ Age in years (\%) } & \multirow{2}{*}{ Total (\%) } \\
\cline { 2 - 4 } & $\mathbf{1 9 - 2 4}$ & $\mathbf{2 5 - 3 0}$ & $\mathbf{3 1} \mathbf{- 3 5}$ & \\
\hline Abortion & $31(34.4)$ & $12(13.3)$ & $3(3.3)$ & $\mathbf{4 6}(\mathbf{5 1 . 1})$ \\
\hline Intrauterine death (IUD) & $11(12.2)$ & $12(13.3)$ & $0(0)$ & $\mathbf{2 3}(\mathbf{2 5 . 6 )}$ \\
\hline Abortion \& IUD & $8(8.9)$ & $9(10)$ & $0(0)$ & $\mathbf{1 7}(\mathbf{1 8 . 9 )}$ \\
\hline Congenital malformations & $1(1.1)$ & $3(3.3)$ & $0(0)$ & $\mathbf{4 ( 4 . 4 )}$ \\
\hline Total & $\mathbf{5 1 ( 5 6 . 7 )}$ & $\mathbf{3 6}(\mathbf{4 0})$ & $\mathbf{3}(\mathbf{3 . 3})$ & $\mathbf{9 0}(\mathbf{1 0 0})$ \\
\hline
\end{tabular}

Table.3 Positive serological evidence for torch infections $(n=90)$

\begin{tabular}{|l|c|c|c|c|}
\hline AGENT & Igm (\%) & Igg (\%) & TOTAL $^{\dagger}(\boldsymbol{\%})$ & Igm \& igg(\%) \\
\hline TOXOPLASMA & $5(5.6)$ & $28(31.1)$ & $33(36.7)$ & $\mathbf{1}(\mathbf{1 . 1})$ \\
\hline RUBELLA & $8(8.9)$ & $48(53.3)$ & $56(62.2)$ & $\mathbf{6 ( 6 . 7 )}$ \\
\hline CMV & $9(10)$ & $60(66.7)$ & $69(76.7)$ & $\mathbf{6 ( 6 . 7 )}$ \\
\hline HSV - 2 & $\mathbf{6 ( 6 . 7 )}$ & $\mathbf{7 ( 7 . 8 )}$ & $\mathbf{1 3}(\mathbf{1 4 . 4})$ & $\mathbf{0 ( 0 . 0 )}$ \\
\hline
\end{tabular}

Total includes IgM + IgG excluding the IgM \& IgG data

CMV was the most seropositive infection followed by rubella and toxoplasma. HSV - 2 was the least.

Table.4 Positive serological evidence for Toxoplasma infection in various age groups $(\mathrm{n}=90)$

\begin{tabular}{|c|c|l|c|c|}
\hline \multicolumn{5}{|c|}{ TOXOPLASMA } \\
\hline Age in years & IgM (\%) & IgG (\%) & TOTAL $^{\dagger}(\mathbf{\%})$ & $\begin{array}{c}\text { IgM \& IgG } \\
(\%)\end{array}$ \\
\hline $\mathbf{1 9}-\mathbf{2 4}$ & $3(3.3)$ & $15(16.7)$ & $18(20)$ & $\mathbf{1}(\mathbf{1 . 1})$ \\
\hline $\mathbf{2 5}-\mathbf{3 0}$ & $2(2.2)$ & $12(13.3)$ & $14(15.6)$ & $\mathbf{0}(\mathbf{0 . 0})$ \\
\hline $\mathbf{3 1}-\mathbf{3 5}$ & $0(0.0)$ & $1(1.1)$ & $1(1.1)$ & $\mathbf{0}(\mathbf{0 . 0})$ \\
\hline TOTAL (\%) & $\mathbf{5 ( 5 . 6 )}$ & $\mathbf{2 8 ( 3 1 . 1 )}$ & $\mathbf{3 3}(\mathbf{3 6 . 7})$ & $\mathbf{1}(\mathbf{1 . 1})$ \\
\hline
\end{tabular}

Total includes IgM + IgG excluding the IgM \& IgG data

Age group of $19-24$ years had the maximum serological evidence of Toxoplasma followed by $25-30$ years age group 
Table.5 Obstetric history of Toxoplasma seropositive cases $(n=33)$

\begin{tabular}{|l|l|c|c|l|}
\hline \multirow{2}{*}{ Clinical Presentation } & \multicolumn{4}{|l|}{ SEROPOSITIVITY } \\
\cline { 2 - 5 } & IgG $(\%)$ & IgM (\%) & IgG \& IgM (\%) & Total (\%) \\
\hline Abortion & $19(57.6)$ & $3(9.1)$ & $1(3)$ & $\mathbf{2 3}(69.7)$ \\
\hline Intrauterine death (IUD) & $6(18.2)$ & $3(9.1)$ & $0(0)$ & $\mathbf{9 ( 2 7 . 3 )}$ \\
\hline Congenital malformations & $1(3)$ & 0() & $0(0)$ & $\mathbf{1}(\mathbf{3})$ \\
\hline Total & $\mathbf{2 6}(\mathbf{7 8 . 8})$ & $\mathbf{6}(\mathbf{1 8 . 2})$ & $\mathbf{1}(\mathbf{3})$ & $\mathbf{3 3}(\mathbf{1 0 0})$ \\
\hline
\end{tabular}

Table.6 Positive serological evidence for rubella infection in various age groups $(n=90)$

\begin{tabular}{|c|c|l|c|c|}
\hline \multicolumn{5}{|c|}{ RUBELLA } \\
\hline Age in years & IgM (\%) & IgG (\%) & TOTAL $^{\dagger}(\%)$ & $\begin{array}{c}\text { IgM \& IgG } \\
(\%)\end{array}$ \\
\hline $\mathbf{1 9}-\mathbf{2 4}$ & $6(6.7)$ & $30(33.3)$ & $36(40)$ & $\mathbf{4 ( 4 . 4 )}$ \\
\hline $\mathbf{2 5}-\mathbf{3 0}$ & $1(1.1)$ & $15(16.7)$ & $16(17.8)$ & $\mathbf{1}(\mathbf{1 . 1})$ \\
\hline $\mathbf{3 1} \mathbf{- 3 5}$ & $1(1.1)$ & $3(3.3)$ & $4(4.4)$ & $\mathbf{1}(\mathbf{1 . 1})$ \\
\hline TOTAL (\%) & $\mathbf{8 ( 8 . 9 )}$ & $\mathbf{4 8}(\mathbf{5 3 . 3})$ & $\mathbf{5 6}(\mathbf{6 2 . 2})$ & $\mathbf{6 ( 6 . 7 )}$ \\
\hline
\end{tabular}

Total includes $\operatorname{IgM}+\operatorname{IgG}$ excluding the IgM \& IgG data

Age group of $19-24$ years had the maximum serological evidence of Rubella followed by $25-30$ years age group.

Table.7 Obstetric history in rubella seropositive cases $(\mathrm{n}=56)$

\begin{tabular}{|l|c|c|c|l|}
\hline \multirow{2}{*}{ Clinical Presentation } & \multicolumn{4}{|l|}{ SEROPOSITIVITY } \\
\cline { 2 - 6 } & IgG (\%) & IgM (\%) & IgG \& IgM (\%) & Total (\%) \\
\hline Abortion & $29(51.8)$ & $1(1.8)$ & $4(7.1)$ & $\mathbf{3 4}(\mathbf{6 0 . 7 )}$ \\
\hline Intrauterine death (IUD) & $19(33.9)$ & $1(1.8)$ & $1(1.8)$ & $\mathbf{2 1}(\mathbf{3 7 . 5})$ \\
\hline Congenital malformations & $0(0)$ & $0(0)$ & $1(1.8)$ & $\mathbf{1}(\mathbf{1 . 8})$ \\
\hline Total & $\mathbf{4 8}(\mathbf{8 5 . 7})$ & $\mathbf{2 ( 3 . 6 )}$ & $\mathbf{6 ( 1 0 . 7 )}$ & $\mathbf{5 6}(\mathbf{1 0 0})$ \\
\hline
\end{tabular}

Table.8 Age wise distribution comparison with other results

\begin{tabular}{|c|c|}
\hline Authors Name & Mean Age Group (\%) \\
\hline P Yasodhara - $2001 \quad(n=247)$ & 22.3 years \\
\hline D Sebastian - 2008 (n=71) & $23.2(49.38 \%)$ \\
\hline M.R. Sen - $2012 \quad(n=380)$ & 23.4 years \\
\hline Nazish - $2014 \quad(n=303)$ & $21-25$ years $(53.84 \%)$ \\
\hline PRESENT STUDY $(\mathbf{N}=90)$ & 22.7 years $(56.7 \%)$ \\
\hline
\end{tabular}

Majority of cases in above studies were in the age group $19-24$ years. 
Table.9 Obstetric history of $\mathrm{BOH}$ cases comparison with other studies

\begin{tabular}{|l|c|}
\hline Authors name \& year & Obstetrical history \\
\hline Shashi Chopra et al., --2004 & Abortions $61(71.8 \%)$ \\
\hline Janak Kishore et al., -- 2011 & Abortions 28 (59.5\%) \\
\hline Padmavathy M et al., --2013 & Abortions $47(54.1 \%)$ \\
\hline Nazish et al., -- 2014 & Abortions 22 (7.26\%) \\
\hline PRESENT STUDY & Abortions 63 (70\%) \\
\hline
\end{tabular}

Table.10 Seropositivity of Toxoplasma comparison with other studies

\begin{tabular}{|c|c|c|c|}
\hline \multirow[t]{2}{*}{ Authors Name - yr } & \multirow[t]{2}{*}{ No of cases } & \multicolumn{2}{|l|}{ Seropositivity } \\
\hline & & $\operatorname{IgM}(\%)$ & IgG $(\%)$ \\
\hline Turbadkar - 2003 & 380 & $40(10.5 \%)$ & $160(42.1 \%)$ \\
\hline Yasodhra et al., 2004 & 100 & $8(8 \%)$ & $33(33 \%)$ \\
\hline Singh S. 2004 & 180 & $6(3.3 \%)$ & $81(45 \%)$ \\
\hline Suryamani et al., 2013 & 80 & $16(20 \%)$ & $36(45 \%)$ \\
\hline Nazish et al., 2014 & 303 & $16(5.28 \%)$ & ----- \\
\hline PRESENT STUDY & 90 & $5(5.6 \%)$ & $28(31.1 \%)$ \\
\hline
\end{tabular}

Table.11 Obstetric history of Toxoplasma seropositive cases comparison with other studies

\begin{tabular}{|l|c|}
\hline Authors Name - yr & Predominant Obstetrical History \\
\hline Shashi Chopra 2004 & Abortions 61 (71.8\%) \\
\hline Rajendra B Surpam 2006 & Abortions $12(27.3 \%)$ \\
\hline Munmun Das Sarkar 2012 & Abortions (51.92\%) \\
\hline Suryamani et al., 2013 & Abortions 20 (38.4\%) \\
\hline PRESENT STUDY & Abortions 23 (69.7\%) \\
\hline
\end{tabular}

Table.12 Seropositivity of Rubella comparison with other studies

\begin{tabular}{|c|c|}
\hline Authors Name - yr & IgM (\%) Seropositivity \\
\hline Ravinder Kaur et al., 1999 (n=120) & $10(8.3 \%)$ \\
\hline Singh et al., - 2003 & $(10.4 \%)$ \\
\hline Arora Usha et al., - $2008 \quad(\mathrm{n}=150)$ & $13(8.67 \%)$ \\
\hline Kishore et al., - 2011 $(\mathrm{n}=60)$ & $9(15 \%)$ \\
\hline B V Ramana et al., $2012 \quad(\mathrm{n}=150)$ & $19(12 \%)$ \\
\hline Nazish et al., - $2014 \quad(\mathrm{n}=300)$ & $14(4.6 \%)$ \\
\hline PRESENT STUDY & $8(8.9 \%)$ \\
\hline
\end{tabular}


Table.13 Obstetric history of Rubella seropositive cases comparison with other studies

\begin{tabular}{|l|c|}
\hline Authors Name - yr & Predominant Obstetrical History \\
\hline Arora Usha et al., 2008 & Abortions $60.7 \%$ \\
\hline Kishore et al., 2011 & Abortions $63.3 \%$ \\
\hline B V Ramana et al., 2011 & Abortions $43.33 \%$ \\
\hline PRESENT STUDY & Abortions $60.7 \%$ \\
\hline
\end{tabular}

In the present study Toxoplasma gondii, which is a known etiological agent in recurrent pregnancy wastage was found positive in $28(31.1 \%)$ IgG and $5(5.6 \%)$ IgM pregnant women with $\mathrm{BOH}$. This is similar to what has been reported earlier. Of the 33 cases reported positive for either $\operatorname{IgM}$ or $\operatorname{IgG}$, 23 cases had previous history of two or more spontaneous abortions while 9 had a history of intrauterine deaths, while only one case had history of previous child with vision defect i.e. congenital malformations. Hence predominant clinical condition responsible for $\mathrm{BOH}$ with Toxoplasma infection was abortions followed by intrauterine deaths (IUD). Abortion was similarly observed as a predominant obstetrical history in other related studies. Shashi Chopra et al., in 2004 observed $61(71.8 \%)$ seropositive cases for Toxoplasma had a previous obstetrical history as abortions. Surpam in 2006 concluded abortions as the most common previous pregnancy wastage. Suryamani Chintapalli, I Jyothi Padmaja in 2013 concluded that 38.4\% seropositive cases had abortions as previous obstetrical history.

Abortions were the most common previous obstetrical outcome in the above studies in Toxoplasma seropositive cases.

Interpretation of Toxoplasma serology according to Burrow and Duffy ${ }^{71}$ is when a positive IgM test result indicates acute/early infection, IgG titres should be retested in several weeks. A positive IgG titre is sufficient to establish that a patient has been infected with Toxoplasma gondii. Recent infection is indicated by a positive test result for both $\mathrm{IgG}$ and $\operatorname{IgM}$, and remote infection is usually indicated by a negative $\operatorname{IgM}$ with the positive IgG test result. A previous history of pregnancy wastage and serological reactions for toxoplasmosis during current pregnancy must be considered while managing bad obstetric history cases so as to reduce adverse foetal outcome.

Present study reinforces that antenatal screening of pregnant mothers for toxoplasma IgM seropositivity is very useful as it reflects primary infection or reactivation phenomenon with pathogen activity in progress. Statistical analysis, although shows that the differences between cases and controls are not significant but the incidence based on seroprevalence suggest that toxoplasma screening in cases with high index of clinical suspicion is important not only in current pregnancy but also for the benefit of future newborn in future pregnancies. Since, the impact of toxoplasma appears later in life of foetus, its evidence, if known earlier would help for follow up on periodic basis and also help clinician prepare better for management of the complications later in life.

\section{Rubella}

Rubella is a well-known viral disease, which typically manifest as a self-limited disease characterized by erythematous maculopapular rash, low- grade fever, and mild respiratory symptoms. Major concern of this disease is its 
occurrence in pregnant women as it can cause a serious, often fatal, congenital rubella syndrome in new-born, especially when infection occurs during the first trimester. As many as $85 \%$ of infants infected in the first trimester of pregnancy will be affected. Several studies in India and other countries showed the seroprevalence of Rubella as $4.66 \%-28.6 \%$ in women of reproductive age group $^{21}$. Enzyme-linked immunosorbent assay (EIA) is used widely because it is readily automated and can easily be included in antenatal screening. (Rubella, 2012).

In the present study, of the 90 cases of $\mathrm{BOH}$ the seropositivities of the pregnant women for anti-rubella $\operatorname{IgM}$ is $8(8.9 \%)$, while $\operatorname{IgG}$ is 48 $(53.3 \%)$. Of these Rubella seropositive females $6(6.7 \%)$ were positive for both $\mathrm{IgG}$ \& IgM. Ravinder Kaur et al., ${ }^{59}$ in 1999 had shown similar observation with IgM positives in $10(8.3 \%)$ of 120 cases. Singh et al., in 2003 have reported higher positivity $(10.4 \%)$ in women with adverse pregnancy outcome as compared with those with normal obstetric performance (3.6\%). Arora Usha et al., in 2008 concluded that Rubella IgM antibodies were demonstrated in $13(8.67 \%)$ cases in study group. Kishore et al., in 2011 concluded similar results with IgM seropositivity in $9(15 \%)$ of 60 cases. Similar results were observed by Ramana et al., in 2012 with IgM anti rubella 12\%. In 2014 Nazish et al., at Aligarh concluded that anti-Rubella Virus IgM were found in $14(4.6 \%)$ of $300 \mathrm{BOH}$ cases.

Similarity of seropositivity of anti-rubella antibodies in present study and other studies from different parts of India.

\section{Age wise distribution of Rubella cases}

Analysis regarding age distribution revealed that the seropositivity is found to be higher in 19 - 24 years age group, 36 (40\%). P.
Yasodhara in 2001 had similar observation with average mean age of 22.8 years. In 2004 N. Singla et al., concluded similar observation. Jubaida et al., in 2011 concluded highest seropositivity of Rubella in the age group of $21-25$ years.

\section{Obstetric history of Rubella seropositive cases}

Overall seropositivity of Rubella concluded in this study is 56 (63\%). Out of these 56 cases of $\mathrm{BOH} 34$ had a history of two or more spontaneous abortions while 21 of them had a history of intrauterine deaths and one case had a history of congenital malformation i.e. hearing defect of her 4 years old child. Arora Usha et al., 2008 observed association of Rubella has been maximum with abortions. In a study by B V Ramana in 2011 within the test group highest percentage $(43.33 \%)$ of sero-positivity was observed in pregnant women with repeated abortions followed by intrauterine death cases (12.73\%).

Abortions were the most common previous obstetrical outcome in the above studies in Rubella seropositive cases. The presence of rubella specific IgG in an unvaccinated population is a long-term marker of previous rubella infection. The present study demonstrates a strong association between the TORCH infectious agents and $\mathrm{BOH}$ in women especially among young aged women. ELISA method is more efficacious than any other methods in demonstrating TORCH elements antibodies.

TORCH infections are associated with recurrent abortion, intrauterine growth retardation, intrauterine death preterm labor, still birth, early neonatal death and congenital malformation.

It may not be possible to screen all pregnant women with $\mathrm{BOH}$ for TORCH as it is 
economically not possible, but all the patients with previous history or recurrent pregnancy miscarriage should be subjected to TORCH screening.

In cases where antibodies are positive, the patient should be advised and counselled about the adverse effect of the TORCH infection on the fetus, due to this the complications such as congenital, malformation, abortion, stillbirth, and preterm deliveries may occur, and the affected female should be counselled with her husband regarding continuation of pregnancy and treatment.

TORCH infections play a role on adverse fetal outcome in current pregnancy so all antenatal cases with $\mathrm{BOH}$, even if asymptomatic should be routinely screened for TORCH agents as early diagnosis to reduce adverse fetal outcome, diminishing the morbidity and mortality.

All pregnant women should have their blood examined for TORCH antibodies. A previous history of pregnancy wastage and the serological reaction for TORCH infections during current pregnancy must be considered while managing $\mathrm{BOH}$ cases so as to reduce the adverse fetal outcome.

\section{References}

Burrow G.N, Ferris T.F, Savoia M.C (1999). Bacterial, fungal and parasitic diseases. Medical complications during pregnancy. 5th ed. Philadelphia, PA: WB Saunders; pp. 295-335.

Chintapalli S, Padmaja I.J (2013). Seroprevalence of toxoplasmosis in antenatal women with bad obstetric history. Trop Parasitol. 3(1): 62-6.

Chopra S, Arora U. Aggarwal A (2004). Prevalence of $\operatorname{IgM}$ Antibodies to Toxoplasma, Rubella and
Cytomegalovirus Infections during Pregnancy. Journal of Medical Education \& Research. 6(4); 190-192.

Daftary S.N, Chakravarti S. (1991). Obstetric disorder in pregnancy. Holland and Brews Manual of obstetrics. $15^{\text {th }}$ ed. New Delhi: B.I. Churchill Livingstone, 138

Dhumme M, Sengupta C, Kadival G, Rathinaswamy A (2007). Yelumani A. National seroprevalence of Toxoplasma gondii in India. J Parasitol, 93: 1520-1.

Fatima N, Sami H, Nabeela, Khan P.A, Khan H.M. (2014). Seroprevalence of TORCH Infection in Patients with Bad Obstetric History in and around Aligarh, Northern India. IJSR, 3(7):432-434.

Jubaida N, Mondal M.E.A, Kawsar N.M (2011). Seroprevalence of Rubella antibodies in pregnant women. JAFMC Bangladesh. 7(1): 20-24.

Kishore J, Misra R, Paisal A, Pradeep Y (2011). Adverse reproductive outcome induced by Parvovirus B19 and TORCH infections in women with highrisk pregnancy. J Infect Dev Ctries. 2011; 5(12): 868-873.

Kumari N, Morris N, Dutta R (2011). Is screening of TORCH worthwhile in women with $\mathrm{BOH}$ : An observational study. J Health PopulNutr. 29(1):77-80

Nagaraja B, Ramana B.V, Murty D.S, Naidu K, Reddy B.K (2012). Prevalence of Toxoplasmosis among antenatal women with Bad Obstetrics History. IJPRBS. 1(3):222-227.

Padmavathy, M., Mangala Gowri, Malini, J., Umapath,y B.L, Navaneeth B.V, Mohit Bhatia, Shruthi Harle., (2013). Seroprevalence of TORCH Infections and Adverse Reproductive Outcome in Current Pregnancy with Bad Obstetric History. J Clin Biomed Sci. 3(2), 62-71. Rubella. Epidemiology and Prevention of Vaccine-Preventable Diseases. The Pink Book: Course Textbook - 12th Ed. 2012 
[internet] Available from: http://www.cdc.gov/vaccines/pubs/pink book/rubella.html

Sadik M.S, Fatima H, Jamil K, Patil C. Study of TORCH profile in patients with bad obstetric history. Biology and Medicine. 4(2): 95-101.

Sebastian D, Zuhara K. F, Sekaran K (2008). Influence of TORCH infections in first trimester miscarriage in the Malabar region of Kerala. African Journal of Microbiology Research, 2: 056-059

Sen M.R, Shukla B.N, Banerjee T. (2012). Prevalence of Serum Antibodies to TORCH Infection in and Around Varanasi, Northern India. Journal of Clinical and Diagnostic Research. 6(9):1483-1485.

Singh S, Munawwar A, Rao S, Mehta S, Hazarika N.K (2014). Serologic Prevalence of Toxoplasma gondii in Indian Women of Child Bearing Age and Effects of Social and Environmental Factors. PLoS Negl Trop Dis. 8(3): e27-37.
Singla N, Jindal N, Aggarwal A (2004). The seroepidemiology of rubella in Amritsar (Punjab). Indian J Med Microbiol, 22: 61-3.

Surpam R.B, Kamlakar U.P, Khadse R.K, Qazi M.S, Jalgaonkar S.V (2006). Serological study for TORCH infections in women with bad obstetric history. J Obstet Gynecol India. 56(1): 41-43

Turbadkar D, Mathur M, Rele M (2003). Seroprevalence of torch infection in bad obstetric history. Indian $\mathrm{J}$ Med Microbiol. 21(2): 108-10

Usha A, Sonia G (2008). Primary rubella infection: Prevalence and relationship to pregnancy wastage. J Obstet Gynecol India. 58(5): 399-401.

Yashodhara P, Ramlaxmi B.A, Naidu A.N, Raman L (2001). The prevalence of the specific IgM which is caused by the Toxoplasma, Rubella, Cytomegalovirus and the C.trachomatis infections during pregnancy. Indian J Med Microbiol. 19: $79-82$.

\section{How to cite this article:}

Rafath Fatima and Sasi Kala, G. 2019. A Study on Age Wise Seroprevalence and Seropositivity for Toxoplasma and Rubella among Torch Infections in Women with Bad Obstetric History. Int.J.Curr.Microbiol.App.Sci. 8(07): 1408-1419. doi: https://doi.org/10.20546/ijcmas.2019.807.168 